\title{
Identidad territorial, agro y políticas públicas. Reflexiones históricas sobre las desigualdades regionales en la Argentina hasta mediados del siglo XX.
}

Noemí María Girbal-Blacha

Universidad Nacional de Quilmes

Resumen

Este estudio histórico se propone abordar -en el escenario de la Argentina Moderna y hasta mediados del siglo XX- las características de la organización del territorio en tanto parte de la identidad nacional, la acción del Estado y su burocracia técnica, así como el alcance de las políticas públicas agrarias, conceptualmente definidas. El objetivo es dar cuenta de los desequilibrios regionales, en un país que concentra alrededor de las tres cuartas partes de su población, su infraestructura y su producción agraria y agroindustrial en una cuarta parte del territorio. Una situación que logra trascender los cambios políticos y gubernamentales ocurridos. Conocer sus causas y consecuencias es parte del desafío que se emprende en estas páginas.

Palabras clave

Territorio; agro ; Argentina ; políticas públicas

Códigos JEL: H11, H32, N16, N56

\author{
TERRITORIAL IDENTITY, AGRO AND PUBLIC POLICIES, \\ HISTORICAL CONSIDERATIONS ABOUT REGIONAL \\ INEQUALITIES IN ARGENTINA UNTIL THE MID-TWENTIETH \\ CENTURY
}

Abstract

This historical research intends to tackle - in Modern Argentina and until the mid-twentieth century - the characteristics of the territorial organization as part of the national identity, the State action and its technical bureaucracy together with the scope of the agrarian public policies, conceptually identified. The aim is to show the regional inequalities in a country that concentrates about three-quarters of its population, its infrastructure and its agrarian production and agro-industrial in one quarter of the territory. A situtation that moves beyond political and governmental changes. One of the challenges of these pages is to know the causes and consequences.

Keywords

Territorial Identity; Agro; Argentica; Public Policies

JEL codes: H11, H32, N16, N56

Fecha de recepción del original: 12 de agosto de 2017; versión definitiva: 12 de marzo de 2019.

Noemí María Girbal-Blacha, Centro de Estudios de la Argentina Rural (CEAR)- Universidad Nacional de Quilmes, Argentina. Investigadora Superior Emérita del CONICET. Argentina

E-mail:noemigirbal@gmail.com.

ORCID ID: 0000-0003-4193-075X. 


\section{Identidad territorial, agro y políticas públicas. Reflexiones históricas sobre las desigualdades regionales en la Argentina hasta mediados del siglo XX.}

Noemí María Girbal-Blacha

Universidad Nacional de Quilmes

1. Territorio, poder, burocracia y políticas públicas: definiciones conceptuales

La conformación del territorio desde la perspectiva rural implica ponderar el papel jugado por el Estado, los principales actores sociales intervinientes en su configuración y las potencialidades diversas del espacio regional con sus especificidades culturales, sabiendo que el sector agropecuario ha jugado y juega un rol significativo en la economía, la política y la sociedad de la República Argentina, con sus casi 3 millones de kilómetros cuadrados.

El modelo agroexportador constituido a partir de las últimas décadas del siglo XIX daría cuenta del éxito del mismo en la región pampeana y áreas circundantes a los puertos de Buenos Aires y Rosario (Santa Fe), como expresión de un sistema de integración jerarquizado y vertical. Al mismo tiempo, tornaba invisibles los desequilibrios interregionales que como el revés de una trama el mismo modelo generaba. Valorizar las identidades territoriales como concepto dinámico que involucra a los actores con el territorio es necesario a la hora de comprender los procesos históricos que definen o influyen en la construcción social del espacio. Las identidades nacen y se vinculan, además, con los valores, con la cultura específica del lugar $y$, en tanto riqueza patrimonial, se enlazan a las estrategias políticas desplegadas para concretar dicho proceso, generalmente gestadas en el caso argentino de espaldas al mercado interno (Benedetto, 2007). Por otra parte, también "el paisaje contribuye a crear identidad y refleja determinados tipos de actitudes identitarias" (Martínez de Pisón, 2010: 14).

En relación con estas características enunciadas, quienes diseñan las políticas públicas que inciden en la legitimidad del sistema político y conforman una burocracia técnica y política de matriz weberiana y como reguladoras institucionales las muestran imbricadas en la acción estatal (Albadalejo, 2014). La burocracia anexa a la articulación normativa no es ajena a las identidades territoriales ni al ejercicio del poder y sus confrontaciones, cuando se atiende a esas particularidades y sus aproximaciones culturales. Se trata de una interacción entre el Estado y la sociedad para gestionar los asuntos públicos que son heterogéneos y complejos.

“En la elaboración e instrumentación de toda política (en cuanto producto intelectual), en el diseño de su sistema operativo, intervienen o pueden intervenir, tres tipos de agentes sociales: los políticos, los burócratas la élite burocrática y los técnicos o expertos, o, también, los intelectuales, ajenos al aparato burocrático" (Gómez Benito, 1995: 321).

Estos agentes integrantes del aparato del Estado permiten conocer la naturaleza de una política concreta. En tal sentido adquiere importancia el asesoramiento y la forma de reclutamiento de estos expertos, porque "la élite burocrática se identifica (ideológica, política, profesional y personalmente) con los políticos responsables del sector del que también son expertos técnicos cualificados y además ideólogo doctrinarios, es decir, "intelectuales"; siendo, por lo tanto, los máximos responsables de la elaboración de la fórmula política agraria y de su fundamentación ideológico-doctrinal, en cuya elaboración se sirven del concurso de otros profesionales y expertos, ajenos a la administración agraria, pero vinculados a ella como asesores ocasionales o permanentes, o por razones profesionales" (Gómez Benito, 1995: 323). La élite burocrática es parte -conforme a estas características- del poder político, del propio poder burocrático e intelectual. En el sistema de relaciones tiene ascendiente sobre los políticos y destaca su superioridad frente a los expertos ajenos a la administración rural. De ahí su peso en la formulación de la política agraria; especialmente en los tiempos del Estado interventor y del Estado de Bienestar. 
Es importante, por las razones expuestas, definir las políticas públicas. Se requiere considerar la autoridad pública, la intervención pública, los actores involucrados en ellas, para poder clasificarlas. Desde este punto de vista, los problemas que deben ser definidos- inducen la raíz de esas políticas, con su retórica y sus marcos interpretativos. También lo hacen con sus estrategias discursivas capaces de permitir a los actores políticos incrementar la legitimidad de sus argumentos (Harguindéguy, 2015: 23-45 y 48). Es necesario considerar que "el saber experto permite evitar el debate ciudadano sobre asuntos potencialmente conflictivos". Ocurre que "la ciencia puede aportar una legitimidad muy importante a un discurso político al apoyar la tesis presentada con datos" (Harguindéguy, 48). Los asuntos políticos tienden entonces a convertirse en asuntos técnicos, cuando "el saber experto facilita una toma de decisión tecnocrática cuyos resultados pueden ser positivos pero que carece de legitimidad democrática" (Harguindéguy, 2015: 48-49). Todos estos aspectos integran el complejo proceso de la puesta en agenda de la toma de decisiones como esencia de la política, como parte de un sistema y un diseño institucional.

La formulación de las políticas públicas "hace referencia a la parte operativa de las decisiones políticas" (Albadalejo, 2014: 67), tanto en sus alternativas como en sus posibles consecuencias para la sociedad. La programación de una política pública implica establecer acuerdos y fijar normas entre los actores implicados. Supone relaciones de poder político y del ejercicio real del poder, en su conceptualización, el diseño de su intervención y su instrumentalización (Albadalejo, 2014: 102-105). Las políticas van más allá del gobierno formal, pueden -y seguramente deben- ser nacionales, pero atendiendo a las especificidades regionales como parte del avance en la institucionalidad y en beneficio de "una aproximación cultural", vinculándose -a su vez- a "la construcción y el fortalecimiento del Estado" (Otalora y Vivas, 2011: 72).

La centralidad de las políticas públicas, "entendidas como acciones estructuradas del Estado, con desempeño nacional, territorial y sectorial" (Otalora y Vivas, 2011: 86), si no contemplan las identidades regionales, generan -al menos- una relación casi simbiótica entre el gobierno central y las elites de esas localidades otorgando consistencia a vínculos de poder verticales que obstaculizan un desarrollo económico equilibrado. El espacio/territorio es una construcción social y responde al modo desigual que los sujetos sociales tienen de capturar los recursos que la sociedad genera. En este contexto y en estrecha relación con la legitimidad se gesta y mantiene la gobernabilidad, como parte del ejercicio del poder y la ejecución de las políticas estatales. El Estado -aunque no es el único- es el principal responsable de mantener la gobernabilidad y la territorialidad como expresión de la múltiple dimensión del poder (Blacha, 2011: 103-119).

Las burocracias también tienen sus perfiles territoriales y en ese sentido promueven la regionalización de las políticas públicas, pudiendo contribuir directamente en la consolidación de los desequilibrios regionales, no ajenos a "la pugna de poder entre burocracias" (Otalora y Vivas, 2011: 79). Sus nexos con el poder central marcarían una mayor o menor presencia sectorial o territorial, sin que estas definiciones impliquen confrontación abierta con quienes detentan la mayor cuota de po- der más allá de la región. Existen -en consecuencia- políticas públicas de matriz regional que se presentan como parte del interés y la responsabilidad del gobierno y la dirigencia nacional. La regulación del Estado -con su dualidad intrínseca- contribuye generalmente a la articulación de las políticas públicas nacionales y regionales, sabiendo que existe una "competitividad territorial", en "función de su infraestructura tecnológica, social e institucional" (Ibarra-Armenta y Trejo-Nieto, 2014: 5152). Control, confrontación y cooperación son parte de estas acciones. En síntesis, las políticas públicas y de gestión pública utilizan variados instrumentos como objeto político; no son neutros, por el contrario, expresan una cierta visión política y moldean también la política (Subirats, Knoepfel, Larrue y Varone, 2012).

El propósito de este estudio histórico es poner, en el escenario de la Argentina Moderna y hasta mediados del siglo XX, la influencia de estos instrumentos conceptualmente definidos, para dar cuenta de los desequilibrios regionales y las desigualdades territoriales, en un país que concentra alrededor de las tres cuartas partes de su población, su infraestructura y su producción agraria y agroindustrial en una cuarta parte del territorio. Una situación que da muestras acabadas de poder trascender los cambios políticos y gubernamentales ocurridos. Conocer sus causas y consecuencias es parte del desafío que lleva adelante en estas páginas.

2. Identidad territorial, políticas públicas y desigualdades en la economía agraria argentina

La Nación Argentina, receptora de inmigración masiva y con una economía basada en el modelo agroexportador, construye socialmente su espacio de manera desigual y de espaldas al pasado aborigen. Las políticas públicas forman parte de la red que sostiene un marcado desequilibrio regional, aunque por acción u omisión dichas políticas tengan como gran ausente las diversidades propias del territorio (Otalora y Vivas, 2011: 90). Este diseño ha seguido un recorrido de modo singular desde la conformación del Estado Nacional, en 1880, que fue a su vez la etapa más próspera de la economía agraria destinada a la exportación, como durante la presencia del Estado intervencionista desde los años treinta y durante los tiempos del Estado Benefactor, dirigista, planificador, nacionalista y popular que se gestó hacia mediados de los años cuarenta. En 1950 -más allá de la redistribución del ingreso en favor de la pequeña y mediana industria- la "vuelta al campo" advierte acerca del significado y la presencia de una Argentina rural heterogénea y compleja, capaz de superar los cambios gubernamentales y las alteraciones en las políticas económicas durante el largo plazo, porque existía referencialmente una "aproximación cultural a las políticas públicas"(Otalora y Vivas, 2011: 91) y sus controversias, que permiten reconocer realidades y capacidades regionales. 
Las diversidades del territorio dan cuenta de: 1) la región pampeana (ganadera, cerealera y directamente vinculada al eje agroexportador a través del puerto); 2) la región agroindustrial: epicentral cuyana, con eje en Mendoza y la del NOA con epicentro en Tucumán (vitivinícola la primera, azucarera la segunda y monoproductoras ambas); y 3) la región marginal del Gran Chaco Argentino en el Nordeste(NEA) de nuestro territorio, dedicado a la explotación forestal, algodonera y yerbatera, que a diferencia de la Patagonia conserva su pertenencia al margen del modelo agroexportador a pesar de no estar aislada, ya que cuenta con vías fluviales y una red ferroviaria conformada por varias compañías que atraviesan y conectan la región con el eje metropolitano (Rofman et al., 2012).

Mapa 1. Regiones agrarias argentinas

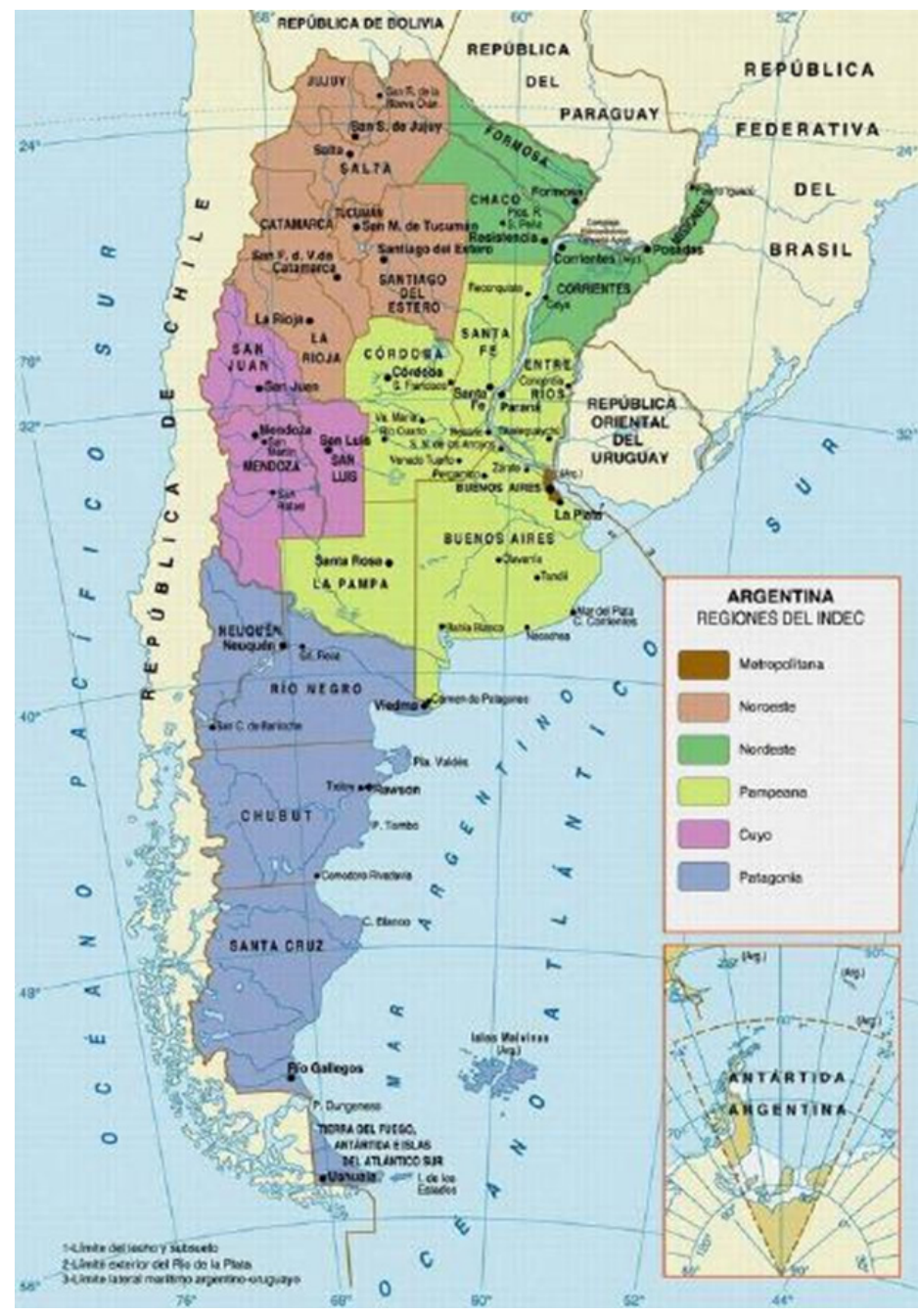

Fuente: http://geosilviald.blogspot.com.ar/
La conjunción de los estudios micro y macro históricos, para plantear la cuestión rural es necesaria porque permite llevar a cabo un enfoque no solo desde la región central de la Argentina agroexportadora (región pampeana), vinculada al eje portuario, sino desde fuera de ella. El desafío es entender la cuestión rural en perspectiva, sin definir la diversidad regional solo a partir de la "región central", sino desde los propios espacios regionales que dibujan la fisonomía del territorio argentino y en estrecha relación con la conformación medioambiental, para comprender -como lo expresa Sergio Boisier (2011) - que la racionalidad regional es cambiante y se vincula con la burocracia en tanto ejecutora de las políticas públicas.

La tierra, en grandes extensiones y concentrada en pocas manos, actuaba no solo como un recurso económico para la producción de materias primas agrarias, sino como símbolo de prestigio social y fundamento del poder político en la Argentina de fines del siglo XIX y gran parte del siglo XX. Conquista y colonización de la tierra pública fueron procesos separados, a diferencia de lo ocurrido en los Estados Unidos.

A la propiedad raíz se sumó la inmigración masiva procedente del sur europeo, mano de obra abundante y barata que permitió transformar la gran aldea en la Argentina Moderna, donde la urbanización creciente y la función del puerto definen los rasgos agroexportadores de la Nación. El régimen de arrendamientos rurales se impuso sobre la colonización, que desde 1876 auspician las leyes nacionales. El comercio exterior, que en un $80 \%$ se concentraba en el puerto de Buenos Aires, y la inversión de capitales externos (ingleses, franceses y estadounidenses especialmente) conformaron una red ferroviaria convergente hacia las ciudades puerto de Buenos Aires y Rosario e impulsaron la industria frigorífica y la infraestructura portuaria. Estas fueron las bases sobre las que se asentó el "granero del mundo", auspiciado por los hombres de la llamada Generación del 80, la de los liberales en lo económico y conservadores en lo político, que le disputaron a la Iglesia su influencia sobre la familia y la educación de una sociedad que aspiraba a modernizarse. Caudillos de élite, que procuraron conformar una identidad nacional basada en el trabajo, la educación pública, el matrimonio y su registro civil, la unidad de moneda y de pesas y medidas, como sustento de ese proceso. "Paz y administración" era la consigna de "los que mandan" en este país de alianzas interoligárquicas sustentadas en el orden y el progreso positivistas. Se trata de los tiempos en que se conformó y arraigó el Estado y el mercado nacional de base oligárquica, donde los actores que operaban eran los ganaderos, los importadores y exportadores del litoral, así como los agroindustriales del interior del país (azucareros y vitivinicultores) para constituir una dirigencia nacional que ejecutaría el proyecto referido (Girbal-Blacha, 2016; Manzanal, 2014).

En el Noroeste -con epicentro en Tucumán- se consolida, a partir de la llegada del ferrocarril en 1876, con el aporte del crédito oficial barato y asociado al poder político, la modernización de la economía azucarera que eliminó cultivos tradicionales como el maíz, producido entonces para exportar en el área circundante al puerto de Buenos Aires y Rosario. En 1877 existían en el país 82 ingenios y 207 cultivadores de caña. En 1895, los ingenios son solo 36 y los cultivadores 2.630. La modernización trajo consigo la concentración empresarial y 
Cuadro 1. Crecimiento desigual en la Argentina Moderna. 1912 (\%)

\begin{tabular}{|l|c|c|c|c|c|}
\hline \multicolumn{1}{|c|}{ Región } & Extensión territorial & Población & Agricultura & Ganadería & FFCC \\
\hline Norte & 25,7 & 16,5 & 4,6 & 13,1 & 16,0 \\
\hline Andina & 17,6 & 9,5 & 4,1 & 4,9 & 9,5 \\
\hline Litoral-centro & 27,7 & 72,7 & 90,5 & 70,1 & 73,0 \\
\hline Patagónica & 28,9 & 1,2 & 0,7 & 12,7 & 1,5 \\
\hline
\end{tabular}

Fuente: Ministerios del Interior, Relaciones Exteriores y Agricultura: Anuario Oficial de la República Argentina. Primer año-1912, Buenos Aires, 1912, p.50.

quien no pudo adaptarse a los cambios, integró las filas de los cultivadores o cambió de ramo. La situación, aunque era próspera, no dejó de ser precaria.

A mediados del decenio de 1890, la crisis de superproducción azucarera mostró los límites de la modernización agroindustrial. Los reclamos del empresariado del azúcar ante el Estado nacional primero y provincial un poco después, no se hicieron esperar. Los propietarios de ingenio se nuclearon en el Centro Azucarero Nacional a partir de 1894 -como lo hicieran en 1866 los ganaderos en la región pampeana en la Sociedad Rural Argentina-y pronto consiguieron la exención impositiva interna y la posibilidad de exportar -hasta 1902- azúcares primados (con aranceles reducidos). Por otra parte, para minimizar los riesgos y diversificar la producción, los ingenios azucareros se transformaron en sociedades anónimas; fundándose la primera de ellas en 1895: la Compañía Azucarera TucumanaCAT S.A. (que nuclea 5 ingenios), propiedad del financiero y comerciante exportador e importador Ernesto Tornquist, también dueño de la única refinería del país: la Refinería Argentina del Rosario (Santa Fe y segundo gran puerto nacional). La CAT S.A. produjo más de un $60 \%$ del azúcar argentino. La presión del sector ante el Estado provincial tucumano aumentó hacia 1902 cuando, con motivo de la Convención Azucarera de Bruselas, los azúcares primados fueron rechazados en los países europeos. Llegó el momento de aplicar la "ley machete" en la provincia de Tucumán (no en todo el NOA), aquélla que dispuso la destrucción de la caña en el surco a cambio de una ajustada indemnización al cañero. El objetivo último era resguardar el precio del azúcar refinado, que se vendía en el mercado consumidor interno, para que los empresarios azucareros cumplieran con los créditos adquiridos ${ }^{1}$.

El poder político y el económico adquirieron notoria identidad y se expresaron en los reclamos y exigencias del empresariado agroindustrial al Estado Nacional y -en mucha menor medida- al provincial que se resistió a esas pretensiones, ya que la presión fiscal se aplicaba a la única actividad económica local próspera: la producción azucarera. La dirigencia política mantuvo entonces una estrecha dependencia del poder económico y actuó en consecuencia. Hasta la primera década del

\footnotetext{
${ }^{1}$ Centro Azucarero Argentino, 1944; Santamaria, 1981; Lenis, 2016; Bravo, 2017.
}

siglo XX los aires del "progreso" llegaron al NOA y a la región de Cuyo, donde, haciendo uso de una negociación similar aunque con una alta burguesía local más abierta-, se impulsó y arraigó la vitivinicultura a partir de 1885, cuando el ferrocarril llegó a Mendoza y se expandió el sistema de irrigación, al amparo de la decisión política y el crédito oficial conveniente. A diferencia de lo ocurrido en Tucumán, aquí el sistema de contratistas y las características artesanales de la producción permitieron una muy adecuada inserción del inmigrante italiano y español, que se capitalizó rápidamente y en no más de quince años se convirtió en propietario de viñedos o en bodeguero, colocándose -en ocasiones y desde la primera década del siglo XX- al frente de importantes sociedades anónimas vitivinícolas (Giol, Gargantini, Tomba, Arizu, entre otras).En ambos casos -el del NOA y el de Cuyo- la concentración regional y empresarial fue el corolario de la crisis y del accionar del Estado en favor de estos agroindustriales monoproductores, que a su vez transformaron y dieron identidad al territorio ${ }^{2}$.

En las áreas marginales, que se incorporaron tardíamente al modelo agroexportador, como la Patagonia en el extremo austral argentino o la región del Noreste (NEA) del país, la inserción en la economía exportadora buscaba evitar la expansión de producciones competitivas con las típicas de la pampa húmeda. Una situación a la cual se sumó para el caso del NEA, la ausencia de una burguesía establecida y el predominio de Territorios Nacionales donde se mantenía una ciudadanía limitada y dependían directamente del gobierno nacional. En el Gran Chaco Argentino -por ejemplo- tal situación se dio a partir de 1895 -cuando ya había fracasado allí la expansión ganadera y azucarera- a través de la explotación forestal, quebrachera, taninera; tanto en la subárea del Chaco santafesino, cercano a las vías fluviales, donde desde los albores del siglo XX asentó su poderío "The Forestal Land, Timber, Railways and Co. Ltd.", dominando la extracción y comercialización de rollizos de quebracho con destino a Europa (Alemania) y los Estados Unidos; como en la subregión del oeste, el Chaco santiagueño, donde se extraía de sus bosques -penetrados por el ferrocarril y a través del obraje- leña, postes y durmientes para el mercado interno, con la participación de inversores 
de la pampa húmeda, quienes aprovecharon la ausencia en la zona de una burguesía preexistente para avanzar sobre las regiones marginales. El propósito que los guiaba era diversificar sus inversiones y minimizar el riesgo, aumentando la renta marginal ${ }^{3}$.

La agricultura se convirtió así, desde el nacimiento de la Argentina Moderna, en el común denominador de la construcción del territorio, trascendiendo las diferencias y especificidades regionales como parte de las exigencias del modelo vigente y producto de una ausencia de políticas públicas que preservaran los recursos naturales y buscaran la diversificación económica.

Hacia 1910, durante los festejos del Centenario de la Revolución de Mayo, la "cuestión social" urbana y rural, resultaba preocupante para el Estado y los sectores dirigentes más altos. Ambos descubrieron entonces los efectos no deseados de la inmigración masiva y acusaron al extranjero venido al país para radicarse y trabajar, de las huelgas y manifestaciones que explicitaron el malestar de los sectores populares. La ley de Defensa Social (que reconoce un antecedente en la ley de Residencia de 1902) intentó contenerla, contrarrestar los efectos de la reacción de obreros urbanos, peones y arrendatarios rurales, pero sin mucho éxito. La situación mostró otra cara de la Argentina del "progreso indefinido"; que resulta menos conveniente pero tan real como aquélla, la del conflicto, la postergación y la dependencia.

La autocrítica desde el sector dirigente dio lugar para la acción a "los liberales reformistas", quienes propiciaron la reforma electoral (1902) e impulsaron el proyecto de código de trabajo (1904), por ejemplo, como medios para descomprimir el malestar social. En materia económica, el fin de la expansión horizontal agrícola estaba próximo. Estaba en jaque la agricultura extensiva. La dirigencia argentina debía sostener el crecimiento más allá de los desajustes visibles del modelo agroexportador, sin renunciar a él o proponiendo la diversificación económica con sentido federal como sostiene la Constitución Nacional. Propuestas que se demoraron en reflejarse en una descompresión de las desigualdades regionales.

3. El Estado Interventor y las políticas públicas subsidiarias para el agro

La crisis internacional de 1929 generó cambios en las condiciones de desarrollo, agravó el convulsionado panorama político, social y económico interno y sus secuelas se manifiestan con rigor en Argentina hacia 1932. Se impuso "la diplomacia del dólar", arraigaron los nacionalismos económicos, el merca-

\footnotetext{
3 Zarrilli, 2016; Girbal-Blacha, 2016; Barsky y Gelman, 2009; Manzanal y Rofman, 1989.
}

do mundial se reorganizó y se acentuó la caída de los precios de los productos primarios. El Estado liberal entró en crisis, se activó la polarización social y se derrumbó el mercado del capital internacional (O'Connell, 1984).

La crisis nacional, orgánica y estructural argentina de 1930 mostró sus múltiples y complejas causas. Sus efectos alcanzaron a todos los planos del quehacer nacional, incluyendo el político-institucional. La Argentina padeció una crisis de identidadque llevó a gran parte de la sociedad a cuestionar a la dirigencia por la falta de respuestas a los desajustes del modelo. Padeció, además, una crisis de dependencia relacionada con el "crecimiento hacia afuera", que comenzó a mostrar sus efectos negativos y generó respuestas de adaptación a las exigencias externas que reforzaron el bilateralismo con Gran Bretaña. Se desplegó una crisis de distribución relacionada con la agudización de los problemas sociales, que reconocía dos niveles: el que se da entre los sectores dirigentes y los sectores bajos de la sociedad y aquél que se manifiesta al interior de la propia dirigencia. Por último, las crisis de participación y de legitimidad, completaron la multicausalidad del proceso, que expresó la ineficacia del sector dirigente para resolver dentro del sistema los problemas nacionales. Como expone Waldo Ansaldi (1989: 321) "el drama reside tanto en la incapacidad de la clase dominante (burguesía terrateniente) para ser dirigente, cuanto en las subalternas para construir un sistema hegemónico alternativo".

Esta "crisis orgánica", que no alcanzó a transformarse en "crisis revolucionaria", mostró los perfiles de un proceso económico atípico (W.W.Rostow, 1960), dejó al descubierto a una dirigencia que mantuvo pendientes viejos problemas y no alcanzó a presentar respuestas acertadas ante los emergentes de esta crisis que afecta al mundo occidental. Se agotó una etapa del desarrollo argentino. La reorganización jurídicoinstitucional colocó al Ejército en la cúpula del poder político y reordenó las relaciones sociales. El país se reinserta en el mercado mundial desde un definido bilateralismo en favor de Inglaterra, las "oportunidades alternativas" que se presentaban ya antes de los años treinta -como la industria- con grupos económicos más diversificados y estrategias empresariales más cercanas al capital comercial o financiero que al productivo, indicaban los cambios en las reglas de juego. Se perdió el "estado de confianza" -al que hace referencia John Keynes-, replanteándose la discusión entre la sociedad y el Estado. La dirigencia se preocupó más por mantener su equilibrio que por su transformación.

Frente a estas condiciones, el Estado argentino replanteó su papel. El golpe de Estado del 6 de setiembre de 1930 fue una respuesta a la frustración de expectativas, más que a una situación de "miseria profunda" o de mantenimiento del "statu quo", dice Leopoldo Allub (1989). En Argentina la crisis golpeó con particular dureza al sector agrario, cuando se llegó al "fin de un paradigma", el del crecimiento hacia afuera. Un año después, la moneda se depreció (un 40\%) por la transferencia de capitales al exterior, se implantó el control de cambios (1931; reformado en 1933 para desdoblar el cambio conforme a las exigencias del Pacto Roca Runciman), que actuó selectivamente como un freno a las importaciones y generó el traslado de ingresos desde el sector agrícola al industrial que -como 
el textil- usaba preferentemente materia prima nacional. La agricultura y la ganadería disminuyeron su participación en el ingreso nacional, que en 1926 era de un 27,5\% y en 1933 descendió al 25,8\%, en tanto la representación de la industria fabril creció de un $17,2 \%$ a un $18,6 \%$ en igual período. La recuperación de la depresión de los años treinta fue financiada por la transferencia de ingresos de los sectores rurales a los urbanos, pero las desigualdades regionales en Argentina se mantuvieron y la organización del territorio no se modificó sustancialmente (Arnaudo, 1987: 163). Las políticas públicas para el agro apostaron a reforzar los subsidios para el sector y el bilateralismo comercial externo.

En 1933, la sostenida declinación en los precios de los cereales nacida a fines de los años veinte llevó a la creación de la Junta Reguladora de Granos, destinada a tonificar el mercado agrícola. El objetivo era regular la comercialización de la producción, evitar ventas precipitadas ante la desvalorización de la moneda corriente, mantener el nivel interno de los precios en beneficio de los productores y fijar oficialmente las cotizaciones para comprar a precios que resulten redituables para el productor. El Estado subsidiaba una vez más -y ahora institucionalmente- al agro. Los productores se amparaban en los alcances de esa política que los beneficiaba para continuar en sus explotaciones y no hacer uso alternativo de la diversificación productiva (Balsa, 1994).

Al mismo tiempo, se promovió la construcción de elevadores de granos para alentar el embarque a granel y en 1932 se creó la Red General de Elevadores de Granos, que en 1935 se constituyó en una Dirección Nacional de Estado; mientras, se dispuso la tipificación de cereales y se organizó el crédito para los agricultores, aunque con muchos requisitos para obtenerlos. Cuando en 1934-35 los precios granarios mejoran, se debió a la prolongada sequía que afectó a Canadá y los Estados Unidos, no a la acción reguladora estatal. Entre 1930-34, los productos agrícolas representaban el 59,8\% del valor total de nuestras exportaciones. El agro pampeano recibió los beneficios de estas buenas cotizaciones hasta 1937.Pero desde 1938, y ante los efectos de la segunda conflagración mundial desde 1939, una nueva caída en las cotizaciones reactivó el accionar de la Junta Reguladora de Granos (O'Connell, 1984).

La crisis de los años treinta también obligó a revisar el débil sistema bancario argentino. En 1935, se llevó adelante la reforma monetaria y bancaria cuando se crearon el Banco Central de la República Argentina, con un capital mixto de 30 millones de $m \$ n$ (10 millones suscriptos por el gobierno) destinado a ajustar la oferta de moneda a la demanda, y el Instituto Movilizador de Inversiones Bancarias, para movilizar los activos fijos. La autoridad monetaria pretendía evitar fluctuaciones de la actividad económica interna ante los vaivenes externos. Mientras tanto, el estallido de la Segunda Guerra Mundial en 1939 aceleró el proceso de industrialización por sustitución de importaciones, sumando sus efectos a las propuestas nacionalistas del Ejército que organizó el golpe de Estado del 4 de junio de 1943, con proclamas favorables a la industrialización. La reorganización del comercio internacional, el asentamiento industrial ( $21 \%$ del PIB), la inflación de precios ante una política de sostén del poder de compra frente a un mercado recesivo en bienes disponibles, provocaron un aumento del ahorro interno con una balanza comercial positiva. En este escenario volvieron a redimensionarse los vínculos entre la identidad territorial, el agro y las políticas públicas (Girbal-Blacha, 1994).

Los productos agrícolas fueron los más afectados por la guerra ante la falta de bodegas y la mejor situación de nuestros competidores en el mercado internacional (Canadá y los Estados Unidos). Al iniciarse el conflicto bélico, el total de la superficie sembrada en la Argentina alcanzaba las 28.360 .700 hectáreas, dedicadas en más de un 73\% a cereales; en 1945 el área quedó reducida a 26.186.000 hectáreas, con un descenso en la superficie cultivada en beneficio de las forrajeras, producto de la buena situación de las carnes en el comercio de exportación. Sin duda, el núcleo del modelo agroexportador resultó más afectado que las producciones de las economías regionales, que mantuvieron una mayor dependencia del mercado interno (Maddison, 1988).

El Estado sostuvo -una vez más- los precios de los granos, mientras los arrendatarios rurales denunciaban a través de la Federación Agraria Argentina -ya desde 1936- violaciones a la Ley Contractual Agraria -reformada en 1932- por parte de los propietarios de tierras. En 1942, la ley 12.771 redujo obligatoriamente el monto en dinero y/o en especie de los arrendamientos, mientras suspendía los desalojos, para evitar éxodos masivos de la población rural. Las economías agroindustriales del interior no merecían especial atención y las desigualdades permanecían más allá de la identidad nacional.

La posguerra renovó las esperanzas del sector, que solo se concretaron después de 1950, cuando se operó el proceso de tecnificación agraria que Adolfo Coscia (1983) denomina la"segunda revolución agrícola". Entre 1930 y 1945, se prepararon los cambios, que fueron más importantes en la zona maicera: una fuerte despoblación del medio rural, progresiva extinción del productor tradicional, gradual urbanización del productor agrario y ampliación de la escala óptima de la empresa agrícola. Los sectores agrarios se reagruparon en corporaciones diferenciadas que los representaban. A las tradicionales Sociedad Rural Argentina (1866), la Bolsa de Cereales (nacida en 1854 como Sala de Comercio Once de Septiembre) y la Federación Agraria Argentina (1912) se sumaron la CAP (1934, Corporación Argentina de Productores de Carnes) y los criadores nucleados en la CARBAP (1932), preocupados por aumentar su influencia en las gestiones estatales que sostiene una burocracia técnica y política como parte del intervencionismo estatal (Blacha, 2015). La Argentina rural ante la diversificación productiva se corporativizó, subrayó su importancia y trató de ajustarse a las nuevas exigencias del mercado mundial.

Las carnes ocupaban un lugar significativo en el comercio exterior argentino. Su destino más importante -y casi exclusivo- era el Reino Unido y dependía de convenios bilaterales. Son los sectores ganaderos quienes nuevamente se dirigieron al Estado y en 1933 se creó la Junta Nacional de Carnes, con oposición de los socialistas y apoyo decidido de la Concordancia y el Partido Demócrata Progresista. Este organismo autárquico ejercía el control del comercio de carnes, fijaba normas de clasificación y tipificaba el producto. El conflicto ya no comprometía solo a criadores e invernadores, se trasladó al sistema político, como lo demuestra en 1933 el Tratado RocaRunciman, impulsado por invernadores, frigoríficos y grandes 
criadores en medio de la oposición parlamentaria y nacionalista. El convenio evitaba restricciones en las importaciones de carne por debajo del $90 \%$ correspondiente al año de 1932; un $85 \%$ de las importaciones quedaban en manos anglo-norteamericanas y un $15 \%$ se reservaba a la C.A.P. Ante la vigencia del control de cambios, Inglaterra obtuvo un cambio favorable para las compras que de allí procedieran, cuando se fijó una base doble de cambio: libre y oficial; se aseguraban divisas disponibles al Reino Unido, equivalentes al monto total del cambio en libras esterlinas que surgían de las ventas de productos argentinos allí. No se gravaron con impuestos el carbón y otros productos de procedencia británica, al tiempo que se aseguraba un "trato benévolo" por parte de la Argentina a las inversiones británicas. Cuando la coyuntura se modificó en la postguerra, la Junta Nacional de Carnes pasó a subsidiar momentáneamente la actividad pecuaria. Una vez más, el Estado salió a proteger al poder agrario a través de políticas públicas específicas que no se extendieron para otros sectores de la economía ajenos al agro (Smith, 1983).

Hacia 1940 se alentaron "cambios estructurales", que atendían el desarrollo del mercado interno. El Ministro de Hacienda Federico Pinedo, presentó entonces ante el Congreso Nacional - para anticiparse a los temidos efectos de la posguerra- el Plan de Reactivación de la Economía Nacional. Plan pro-aliado y primer documento de Estado donde se intentaba modificar parcialmente la estrategia de desarrollo económico vigente. Era de carácter industrialista, procuraba conciliar industrialización y economía abierta, fomentando el comercio con los Estados Unidos y creando un mercado de capitales. Proponía un programa de préstamos industriales, aumentando la construcción de viviendas, revisando las tarifas aduaneras y promoviendo la adquisición por parte del gobierno de los saldos exportables agrícolas no colocados. En síntesis, trataba de mantener abierta la economía "oficializando" la industrialización, pero dejando claramente establecido que el agro seguía siendo "la gran rueda de la economía" y que la industria actuaría a la manera de engranajes secundarios, cuyo funcionamiento se activaría cuando aquélla tuviera dificultades (Llach, 1984).

La propuesta de Pinedo daba cuenta de la creciente hegemonía de las posiciones industrialistas, pero también de las dificultades por las que atravesaba el comercio internacional y de la necesidad de dinamizar la alicaída demanda interna. La acción estatal se veía como la única alternativa. El tránsito del intervencionismo al dirigismo estatal en la economía avanzó. Pinedo propuso movilizar los recursos financieros a través del Banco Central como ente de colocación en el mercado de bonos de ahorro y promoviendo la transferencia y movilización de los depósitos bancarios. La falta de apoyo político que lideraban el General Agustín P. Justo y el radical Marcelo T. de Alvear hizo naufragar el plan propuesto; "modernizante" pero tardío, con muchas cláusulas provisorias y sin contar con el respaldo de una amplia alianza socio-política, que más allá de sus principios seguía proponiendo política públicas que favorecían al agro.Frente a los cambios, los sectores agrarios se reorganizaron y el 24 de febrero de 1943 fundaron Confederaciones Rurales Argentinas (CRA). Mientras, el país aguardaba "la vuelta a la normalidad" y se aprestaba a ponderar en sus propuestas futuras el mercado interno.
Un balance de la coyuntura del período 1930-1943 muestra la vigencia de una política de contraste que se enlazaba a la vulnerabilidad propia de una economía abierta como la argentina. Por un lado, el propósito, alentado desde el poder, era restaurar la hegemonía agroexportadora, frente a un comercio mundial limitado. Por otro, se destacaba la creciente importancia del sector industrial en medio de bajas tasas de inversión. En esta etapa había dos grandes sectores sociales ausentes, paradójicamente los más desarrollados por las nuevas condiciones económicas: la burguesía industrial -inconmovible frente al fracaso del Plan Pinedo y el predominio de los intereses del agro- y la clase obrera, que no se encontraba representada por ninguna de las fuerzas políticas actuantes en la Argentina de entonces.

\section{Confrontaciones y acuerdos en tiempos del Estado Benefac-} tor

El triunfo de Juan Domingo Perón -líder programático del golpe de 1943- en las elecciones presidenciales de febrero de 1946, profundizó una economía volcada al mercado interno y puesta al servicio de amplios sectores populares. Una política económica mercadointernista, que condujo un Estado nacionalista y popular, dirigista y planificador, que se sostuvo en la redistribución del ingreso en favor de la clase obrera y de la pequeña y mediana industria que producía para ese mercado interno expandido, en la Argentina acreedora de postguerra. La alianza entre los sectores más nuevos y pujantes de la burguesía industrial y la clase obrera organizada, con la garantía estatal, definían la esencia del flamante gobierno populista de Juan Perón ${ }^{4}$. El viraje supuso un cambio en el sistema de intereses económicos dominantes y en la estructura de poder existente, para encarar las soluciones a las crisis de dependencia y distribución que en 1930 quedaron al descubierto. El Estado peronista, afirmándose en la doctrinaria y pendular "tercera posición", se orientó, en consecuencia, a consolidar la autonomía económica del país, como hilo conductor y motor de ese proceso que aspiraba a construir una Nación "socialmente justa, económicamente libre y políticamente soberana"5.

Para remontar la crisis de distribución, acreditó a su favor los beneficios de la reforma financiera de 1946 que estatizó la banca, considerando patrimonio nacional el capital del Banco Central de la República Argentina, al mismo tiempo que nacionalizó los depósitos para dar al Estado libertad de acción en materia de política monetaria y crediticia. Llevó a cabo un diagnóstico socioeconómico, a través del Consejo Nacional de

\footnotetext{
4 Murmis y Portantiero, 1965; Waldman, 1981; Lattuada, 1986; Pereyra, 1988; Álvarez Junco y González Leandri, 1994; Girbal-Blacha, López Ortiz y Regina de Mendonca, 2016: presentación y capítulos 6 y 7

5 El Manual del Peronista, Buenos Aires, 1948.
} 
Postguerra, y elevó al rango de entidad autárquica al Instituto Argentino para la Promoción del Intercambio (I.A.P.I.) que monopolizó el comercio exterior argentino y se convirtió en eje del proceso de redistribución del ingreso en favor de la pequeña y mediana industria nacional a través de la banca nacionalizada (Novick, 1986).

Estos instrumentos financieros, económicos y políticos permitieron cumplir con los objetivos del Primer Plan Quinquenal que entró en vigor en 1947, poniendo en los sectores agrarios el mayor peso del cambio que se opera entonces en la economía argentina, aunque el crédito oficial a la producción agropecuaria nunca fuera interrumpido. Se inició entonces y hasta 1949, una etapa de expansión económica en la cual -y a pesar de las advertencias del discurso oficial- el sector rural jugaba un papel estratégico significativo. Discusiones, confrontaciones y acuerdos signaron el diálogo entre el Estado, empeñado en tomar distancia de los rasgos más tradicionales de la Argentina agroexportadora sin prescindir de ella, y los distintos actores sociales agrarios, dispuestos a responsabilizar al gobierno de los altibajos del sector rural. Ni uno ni otros renunciaron a los beneficios que directa o indirectamente ofrecía el cambio de política económica. La política agraria desplegada desde el Estado peronista, tanto antes como después de 1950, se nutrió de controversias y acuerdos que reforzaron el papel primordial jugado por este sector de la producción en la economía nacional (Girbal-Blacha, 2011).

En noviembre de 1943, el gobierno concedió una rebaja obligatoria del $20 \%$ en el precio de los arriendos; manteniendo en vigencia la prórroga de contratos y la suspensión de los juicios de desalojo establecidos por la ley 12771 de 1942. La Federación Agraria Argentina se entusiasmó con estas medidas, las cuales consideraba un paso previo a la resolución del histórico problema de la tenencia de "la tierra para quien la ocupa y la trabaja", que desde 1944 fue impulsada por el Consejo Agrario Nacional. El Manual del Peronista (1948), recogiendo palabras de Juan Perón, proclamaba que "el que tenga la tierra ha de laborarla; y el que no pueda pagar peones, debe trabajarla personalmente. Por otra parte, si no es capaz de trabajarla, que la venda".

El discurso parece encerrar un mensaje favorable a laanunciada "reforma agraria", que sin embargo daría paso a un proceso de desinversión en el agro, cada vez que las prórrogas sucesivas de los contratos de arrendamiento provocaban la no rotación productiva, con la consiguiente pérdida de fertilidad del suelo y menores rindes; así como, un escaso compromiso de parte de arrendatarios y propietarios para reinvertir parte de su renta en el campo, del cual no podían disponer libremente. El propósito del oficialismo era mantener el equilibrio intersectorial entre propietarios, arrendatarios y exportadores, para evitar un desgaste del poder político y la puesta en tensión de todo el sistema. Sin incentivos económicos, el área sembrada retrocedió, pasando de 27.598 .400 hectáreas en el año agrícola 1946-47 a23.577.400 hectáreas en 1950; en tanto, entre 1946 y 1949 el volumen de la producción agrícola declinó en más de un 10\%. El Ilamado "país embudo", que organiza el territorio en torno al eje metropolitano y la pampa húmeda, siguió teniendo vigencia, más allá del cambio en las políticas públicas que no lograban sostenerse en el tiempo.
La proliferación de sociedades anónimas agrarias, inmobiliarias, constituidas desde la segunda mitad del decenio de 1940, con la participación de familiares de los propietarios originales -que la Federación Agraria Argentina denuncia como una "simulación del fraccionamiento de los latifundios"- es el revés de la trama, de la cual el discurso oficial u opositor no dio cuenta.Las expectativas de los actores sociales rurales, arrendatarios y propietarios, frente al accionar del gobierno peronista fue acrecentando. Ambos esperaban definiciones. El Estatuto del Peón Rural de 1944, que reglamentaba las condiciones laborales de los asalariados agrarios permanentes, el Estatuto del Tambero-Mediero de 1946, la atención prestada al Centro de Oficios Varios que sindicalizaba a los peones estacionales o transitorios, así como la propuesta de reforma agraria sustentada por el Consejo Agrario Nacional, la entrega de títulos provisorios de propiedad, algunas expropiaciones y un gran despliegue propagandístico, fueron decisiones que, aunque adoptadas antes de 1946, el peronismo hizo suyas; pero que no se profundizaron después del ascenso de Juan Domingo Perón al gobierno de la República (Lattuada, 1986).

El discurso del líder y los funcionarios de la "Nueva Argentina" confrontaba, mientras omitía explicitar acuerdosque algunos hechos señalan. La titularidad de la cartera de Agricultura durante los inicios de la gestión peronista, entre 1946 y 1947, por ejemplo, quedó en manos del hacendado Juan Carlos Picazo Elordy, con intereses agropecuarios en Santa Fe, Córdoba y Buenos Aires, miembro del Directorio de la firma "Carlos A. Fossatti y Cía S.A., Comisiones y Mandatos" y hombre de la tradicional Sociedad Rural Argentina que representaba desde 1866 los intereses de los grandes estancieros y terratenientes, especialmente asentados en la rica pampa húmeda. También,quien lo sucedió, el ingeniero agrónomo Carlos Alberto Emery, pertenecía a la Asociación Criadores de Ganado Holando Argentino y había desempeñado como técnico en la usina de productos lácteos "La Vascongada" durante la década de 1930. Las reformas sociales, que se dirigían a beneficiar a los sectores más bajos del campo, fueron presentadas por el Ejecutivo Nacional como indispensables para la evolución de la empresa agraria, que debía amortiguar potenciales conflictos y cobraban especial difusión a través del discurso. No ocurre lo propio con el crédito que siguió recibiendo algunos grandes estancieros y empresarios agroindustriales, que la documentación bancaria registra ${ }^{6}$.

La planificación económica peronista obligó a sostener una producción agropecuaria creciente y minimizar el conflicto social, para hacer posible la redistribución del ingreso propuesta. Perón contó para lograr esos fines con dos instrumentos de financiación: el I.A.P.I. y la reforma bancaria de 1946, ya mencionados. El primero comercializaba la producción agraria, comprando a precios mínimos al productor y vendiendo en un mercado mundial que por entonces pagaba precios altos por los cereales. La diferencia así generada constituía el capital para implantar una política crediticia que, a partir de esa reforma financiera, se ajustaba a los objetivos fijados por el Estado ${ }^{7}$.

\footnotetext{
6 ¿Quién es quién en la Argentina? Biografías contemporáneas, Buenos Aires, Editorial Kraft Ltda., 1947.

7 Archivo del Banco Industrial de la República Argentina, 1954.
} 
En 1948, el presidente de la Sociedad Rural Argentina, José Alfredo Martínez de Hoz, al inaugurar la exposición rural de Palermo, se preguntaba: ¿qué sería de la industria y del comercio si desapareciese la riqueza rural?", reclamando definiciones al gobierno nacional. "Pobre país [añadía] el que tiene una ganadería deprimida, sofocada o aletargada por la incertidumbre, la inestabilidad y la falta de incentivo para trabajar"; invitando al Estado a impulsar una actividad agropecuaria progresista, próspera, en un clima de "precios remuneradores y estabilidad económica y social". El campo hizo oír así su reclamo frente a una política económica que ponía el acento en la expansión industrial, redistribuyendo a través del crédito la renta agraria. De todos modos, más allá de las advertencias del discurso oficial y de los subsidios a la industria, los sectores agrarios no quedaban excluidos delacceso alcrédito oficial. El crédito no era un instrumento de confrontación. Los bajos precios que el I.A.P.l. pagaba a los productores rurales, la prórroga de los contratos de arrendamiento, el congelamiento de los cánones de arriendo de los campos y el aumento de los salarios rurales, distorsionaban las relaciones agrarias e influían en el decrecimiento del área sembrada. Al mismo tiempo, las posturas del sector agrario frente al proceder estatal se dividían y variaban según el grado de diversificación inversora de la cúpula agraria, aunque parte de ese deterioro se reparaba con el apoyo oficial que llegaba a través del crédito concedido aun para que los patrones y propietarios pudieran pagar las mejoras sociales acordadas por el oficialismo a los peones rurales ${ }^{8}$.

Hacia 1949-50 cambió la coyuntura internacional. Descendieron los precios agrícolas mundiales ante las abundantes cosechas de Europa, el Canadá y los Estados Unidos de América del Norte y la inflación -después de la reforma de la Carta Orgánica del Banco Central (1949) que suprimió la relación entre emisión y reservas- jaqueaban la economía argentina. El plan económico peronista mostraba sus limitaciones. El sistema financiero puesto al servicio del Estado permitió un rápido "cambio de rumbo" y "la vuelta al campo" se llevó a cabo, iniciándose otro ciclo económico para la "Nueva Argentina". La caída mundial de los precios agrícolas redujo los beneficios obtenidos por el I.A.P.I. y la economía argentina se tornó más liberal (Girbal-Blacha, 2000). En los umbrales de los años cincuenta, la inversión externa se ponderó en otros términos y el discurso oficial cambió su lenguaje, aunque sin dejar de lado la confrontación; la sociedad argentina ya no se dividía en pueblo vs. oligarquía, sino en peronistas vs. antiperonistas, obligando a los actores sociales a definirse políticamente (Laclau, 1987; De Ipola, 1999).

Al inaugurar las sesiones legislativas, el $1^{\circ}$ de mayo de 1950, el presidente Juan Perón advertía que "el sentido de nuestra independencia económica no es de orden aislacionista", añadiendo -en respuesta a las críticas opositoras- que "todo cuanto hemos hecho ha sido precisamente para asegurar un promisorio porvenir a la economía agropecuaria". El nuevo mensaje llega a toda la sociedad". "El presidente de la República, General Juan Perón, aconseja producir más y con-

\footnotetext{
8 PRESIDENCIA DE LA NACIÓN, s/f.

${ }^{9}$ CÁMARA DE SENADORES DE LA NACIÓN, Diario de Sesiones 1950, Buenos Aires, 1950. Mensaje de apertura de las sesiones legislativas.
}

sumir menos", destacaba un libro de lectura de esa época utilizado por los niños de los primeros grados de la escolaridad primaria. En tanto, el 2do. Plan Quinquenal al alcance de los niños(para quinto y sexto grados del ciclo primario) informaba que "Perón quiere que el campo produzca mucho y que su población humana sea feliz [...] Las asociaciones de campesinos o cooperativas le facilitarán la maquinaria para poder producir máscon menos trabajo. El Gobierno fijará los precios más altos a los productos del campo [...] En todas las escuelas se difundirá la benéfica acción del campo. Muchos niños y jóvenes, se dedicarán a las tareas agropecuarias"10.

\section{Reflexiones finales}

La economía argentina de los años cincuenta se contrajo frente a los cambios externos e internos. Los reajustes financieros promovían la inflación sostenida. Una vez más, la mirada de la dirigencia nacional se dirigía al campo, a la espera de encontrar allí soluciones rápidas y seguras para paliar la crítica situación económica. El I.A.P.I. modificó su operatoria y subsidió la producción rural, que después de las sequías de 1951/52, inició una etapa de recuperación. La importación de maquinaria agrícola -con cambio preferencial- los créditos de habilitación rural generalizados ahora para todos los productores agrarios y la adquisición de la producción cerealera a valores subsidiados aumentaron la rentabilidad de los productores, como parte de las estrategias impulsadas desde el Estado; quien se aproximaba entonces al cooperativismo para bajar los costos de intermediación. Con este cambio de rumbo, el I.A.P.I. se endeudó con el sistema bancario oficial y al ser liquidado en 1956 su deuda se calcula en 20.000 millones de pesos.

El presidente Juan Domingo Perón reconocía en 1951 que "lo justo es que ahora la independencia económica sirva al bienestar del campo argentino"11; más allá de las malas cosechas (1951/52) afectadas por la sequía, que acentuaban las dificultades económicas y obligaban al gobierno a profundizar sus definiciones. La crisis alcanzó su máxima expresión en 1952. Entonces el Ejecutivo Nacional dio a conocer el Plan Económico de Emergencia para acentuar la producción y reducir el consumo, revisar las disposiciones sobre trabajo rural que impedían a los productores usar sus propios medios de transporte y solicitaba la colaboración de las organizaciones patronales y obreras para eliminar de los convenios laborales toda circunstancia capaz de limitar la producción sin causa justificada. Se hicieron menores concesiones a los asalariados del campo, mientras se reducía al mínimo la intervención estatal

\footnotetext{
10 2do. Plan quinquenal al alcance de los niños, Buenos Aires, Ed. Luis Lasserre, 1953, pp. $s / n$.

11 CAMARA DE SENADORES DE LA NACIÓN: Diario de Sesiones 1951, Buenos Aires, 1951. Mensaje de apertura de las sesiones legislativas.
} 
para entregar la tierra en propiedad a los productores arrendatarios. El esfuerzo se orientaba a colonos y pequeños arrendatarios para que mejoraran los rindes. Estas acciones reforzaban las bases de poder de los grandes propietarios y estancieros, quienes tendrían un papel importante en el derrocamiento de Perón (setiembre de 1955) y en la política económica implementada por los hombres de la "Revolución Libertadora".

El trayecto recorrido desde los tiempos de la Argentina Moderna de fines del siglo XIX a los de la Nueva Argentina peronista, muestra los recodos y la heterogeneidad del proceso de identidad nacional, como parte de la organización del territorio con base rural y agroindustrial, en el marco de políticas públicas alternas y cambiantes -que las explicaciones historiográficas generales referidas al tema no siempre destacan- para dar cuenta de un histórico desequilibrio regional, que no se corrige con acuerdos crediticios y subsidios en favor del agro como propone el Estado. El Ilamado "país embudo", que converge hacia la ciudad puerto de Buenos Aires, se mantuvo trascendiendo los aportes de la burocracia técnica que cobraron especial significado en los años de 1930 y aun se impuso a la doctrinaria "justicia social" peronista. Las desigualdades regionales expresaban una forma de organización territorial dominada por el modelo agroexportador y sus consecuencias, más allá de las acciones del Estado y de las políticas públicas implementadas, reflejaban la decisión adoptada desde la cúpula del poder, cuando resuelve dejar de "profesar una ortodoxia para con los mandatos de la realidad, que suele contrastar con las ortodoxias doctrinarias", como afirmara Arturo Jauretche al asumir, en 1946, su cargo de Presidente del Banco de la Provincia de Buenos Aires (Girbal-Blacha, 1993:1)12. La autodenominada Revolución Libertadora - del 16 de setiembre de 1955-y la consecuente ruptura de la hegemonía propusieron otro escenario, en el cual los desequilibrios interregionales siguieron vigentes y hubieron de profundizarse frente a la ausencia de políticas públicas agrarias correctoras capaces de sostenerse en el mediano y largo plazo.
Bibliografía

¿Quién es quién en la Argentina? Biografías contemporáneas, Buenos Aires, Editorial Kraft Ltda., 1947.

2do. Plan quinquenal al alcance de los niños, Buenos Aires, Ed. Luis Lasserre, 1953, pp. s/n.

ALBADALEJO, Gema Pastor (2014): Teoría y práctica de las políticas públicas, Valencia, Tirant Lo Blanch.

ALLUB, Leopoldo (1989): "Estado y sociedad civil: patrón de emergencia y desarrollo del estado argentino (1810-1930)", en Waldo Ansaldi y José Luis Moreno (comps.), Estado y sociedad en el pensamiento nacional. Antología conceptual para el análisis comparado, Buenos Aires, Cántaro, pp. 109-157.

ÁLVAREZ JUNCO, José y GONZÁLEZ LEANDRI, Ricardo (1994): El populismo en España y América, Madrid, Editorial Catriel.

ANSALDI, Waldo y MORENO, José Luis (comps.) (1989): Estado y sociedad en el pensamiento nacional. Antología conceptual para el análisis comparado, Buenos Aires, Cántaro.

ARCHIVO DEL BANCO INDUSTRIAL DE LA REPUBLICA ARGENTINA (1954): Informes sintéticos acerca de las condiciones económicas de las diversas ramas de la industria argentina, Buenos Aires, 3 tomos, mimeo.

ARNAUDO, Aldo (1987): Cincuenta años de política financiera argentina (1934-1983), Buenos Aires, El Ateneo.

BALSA, Juan Javier (1994): La crisis de 1930 en el agro pampeano. La burguesía rural media ante la Depresión, Buenos Aires, CEAL.

BARSKY, Osvaldo y GELMAN, Jorge (2009): Historia del Agro Argentino. Desde la Conquista hasta comienzos del siglo XXI, Buenos Aires, Sudamericana, tercera edición.

BENEDETTO, Andrea (2007): “Valorización de la identidad territorial, políticas públicas y estrategias de desarrollo territorial en los países del Mercosur", Revista Opera, 7, pp. 139-195.

BLACHA, Luis Ernesto (2011): “La burocracia como tecnología social. Una mirada sociológica del intervencionismo estatal (1930-1943)", en Martha Ruffini Y Luis E. Blacha, (comps), Burocracia, tecnología y agro, Rosario, Prohistoria Ediciones, pp. 103-119.

BLACHA, Luis Ernesto (2015): La clase política argentina, 1930-1943. La oposición ausente y la pérdida de poder, Bernal, Universidad Nacional de Quilmes.

BOISIER, Sergio (2011): "El territorio en la contemporaneidad (La recuperación de las políticas territoriales)", Revista Líder, 18, pp. 9-24.

BRAVO, María Celia (coord.) (2017): La agricultura: actores, expresiones corporativas y políticas, Buenos Aires, Imago Mundi.

CENTRO AZUCARERO ARGENTINO (1944): Cincuentenario del Centro Azucarero Argentino. Desarrollo de la industria en medio siglo, Buenos Aires, C.A.A.

CERDA, Juan Manuel (2011): Condiciones de vida y vitivicultura. Mendoza 1870-1950, Bernal, Universidad Nacional de Quilmes.

COSCIA, Adolfo (1983): Segunda revolución agrícola en la región pampeana, Buenos Aires, CADIA.

DE IPOLA, Emilio (1999): "El hecho peronista", en Carlos Altamirano (ed.): La Argentina en el siglo XX, Buenos Aires, Ariel, pp. 325-332.

El Manual del Peronista, Buenos Aires, 1948.

GIRBAL-BLACHA, Noemí M. (1993): Historia del Banco de la Provincia de Buenos Aires. Gestión del Doctor Arturo Jauretche (1946-1950), Buenos Aires, Ediciones del Banco de la Provincia de Buenos Aires.

GIRBAL-BLACHA, Noemí M. (1994): “La Argentina en crisis (1890, 1929, 1989). Raíces históricas", Boletín de la Academia Nacional de la Historia (Buenos Aires), LXII-LXIII, pp. 151-184.

GIRBAL-BLACHA, Noemí M. (2000): "Acerca de la vigencia de la Argentina agropecuaria.Estado y crédito al agro durante la gestión peronista (19461955)", The Americas, 56-3, pp. 77-102.

\footnotetext{
12 Girbal-Blacha, 1993, (epígrafe): 1
} 
GIRBAL-BLACHA, Noemí M. (2011): Mitos, paradojas y realidades en la Argentina peronista (1946-1955). Una interpretación histórica de sus decisiones político-económicas, Buenos Aires, Universidad Nacional de Quilmes.

GIRBAL-BLACHA, Noemí M. (2016): “Perfiles históricos de la Argentina rural: agro y política (1880-1970)", História: Debates e Tendencias, 16-1, pp. 1736.

GIRBAL-BLACHA, Noemí M.; LÓPEZ ORTIZ, María Inmaculada y REGINA de MENDONCA, Sonia (coords.) (2016): Agro y política a uno y otro lado del Atlántico. Franquismo, salazarismo, varguismo y peronismo, Buenos Aires, Imago Mundi.

GÓMEZ BENITO, Cristóbal (1995): Políticos, burócratas y expertos. Un estudio de la política agraria y la sociología rural en España (1936-1959), Madrid, Siglo XXI.

HARGUINDÉGUY, Jean-Baptiste (2015): Análisis de políticas públicas, Madrid, Tecnos.

IBARRA-ARMENTA, Cristina Isabel y TREJO-NIETO, Alejandra Berenice (2014): "Competencia territorial: un marco analítico para su estudio", Economía, sociedad y territorio, 44, pp. 49-78.

LACLAU, Ernesto (1987): “Populismo y transformación del imaginario político en América Latina", Boletín de Estudios Latinoamericanos y del Caribe, 42, pp. 25-38.

LATTUADA, Mario J. (1986): La política agraria peronista (1943-1983), Buenos Aires, CEAL, 1986.

LENIS, María (2016): Empresarios del azúcar. Corporaciones, política y discursos. Tucumán (1894-1923), Buenos Aires, Imago Mundi.

LLACH, Juan José (1984): “El Plan Pinedo de 1940, su significado histórico y los orígenes de la economía política del peronismo", Desarrollo Económico, 92, pp. 515-558.

MADDISON, Angus (1988): Dos crisis: América y Asia 1929-1938 y 1973-1983, México, FCE.

MANZANAL, Mabel (2014):“Desarrollo. Una perspectiva crítica desde el análisis del poder y del territorio", Realidad Económica, 283, pp. 17-48.

MANZANAL, Mabel y ROFMAN, Alejandro (1989): Las economías regionales de la Argentina. Crisis y políticas de desarrollo, Buenos Aires, CEAL/CEUR.

MARTÍNEZ DE PISÓN, Eduardo (2010): "Valores e identidades", en Eduardo Martínez De Pison Y Nicolás Ortega Cantero (eds.), El paisaje: valores e identidades, Madrid, Ediciones de la Universidad Autónoma de Madrid, pp. 11-45.

MURMIS, Miguel y PORTANTIERO, Juan Carlos (1965): Estudio sobre los orígenes del peronismo, Buenos Aires, Siglo XXI.

NEFFA, Julio César (1998): Modos de regulación, regímenes de acumulación y sus crisis en Argentina (1880-1996). Una contribución a su estudio desde la teoría de la regulación, Buenos Aires, EUDEBA.

NOVICK, Susana (1986): I.A.P.I.: auge y decadencia, Buenos Aires, CEAL.

O'CONNELL, Arturo (1984): "La Argentina en la Depresión: los problemas de una economía abierta", Desarrollo Económico, 92, pp. 479-514.

OTALORA BUITRAGO, Adriana y VIVAS CORTES, Omar Augusto (2011): “Aproximación cultural a las políticas públicas: burocracia descentralización y ciudadanía", Equidad y Desarrollo, 15, pp. 69-99.

PEREYRA, Horacio (1988): Algunas hipótesis para el análisis del peronismo (1945-1955), Buenos Aires, Biblos.

PRESIDENCIA DE LA NACIÓN (s/f): El campo recuperado por Perón (19441952), Buenos Aires.

RICHARD JORBA, Rodolfo (2008): “Los empresarios y la construcción de la vitivinicultura capitalista en la provincia de Mendoza (Argentina), 18502006", Scripta Nova. Revista electrónica de Geografía y Ciencias Sociales, XII-271, 2008. http://www.ub.edu/geocrit/sn/sn-271.htm

ROFMAN, Alejandro et al. (2012): “La evolución territorial del desarrollo económico-social en el nuevo régimen de acumulación", en Alejandro Rofman et al., Las economías regionales. Luces y sombras de un ciclo de grandes transformaciones 1995-2007, Buenos Aires, Universidad Nacional de Quilmes/Centro Cultural de la Cooperación, pp. 181-202.
ROSTOW, Walt Whitman (1960): The Stages of Economic Growth: A Non-Communist Manifesto, Londres, Cambridge University Press.

SANTAMARÍA, Daniel J. (1981): Azúcar y sociedad en el Noroeste Argentino, Buenos Aires, Ediciones del IDES.

SMITH, Peter (1983): Carne y política en la Argentina, Buenos Aires, Paidós (prim. reimpresión).

SUBIRATS, Joan; KNOEPFEL, Peter; LARRUE, Corinne y VARONE, Fréderic (2012): Análisis y gestión de políticas públicas, Barcelona, Ariel.

WALDMAN, Peter (1981): El peronismo 1943-1955, Buenos Aires, Editorial Sudamericana.

ZARRILLI, Adrián G. (2016): “Ambiente, producción y mercado. El impacto transformador en una economía periférica, el Gran Chaco Argentino en el siglo XX", Areas. Revista Internacional de Ciencias Sociales, 35, pp. 121139. 